\title{
Is screening for Celiac Disease Needed in Patients with Liver Disease?
}

\author{
Janaína Luz Narciso-Schiavon*, Leonardo L. Schiavon \\ Department of Internal Medicine, Division of Gastroenterology, Federal University of Santa Catarina, Santa Catarina, Brazil \\ *Corresponding author: janaina.narciso@uol.com.br
}

Received June 16, 2015; Revised June 17, 2015; Accepted June 24, 2015

\begin{abstract}
Celiac disease is known for its classic clinical manifestations such as anemia and diarrhea. Liver involvement in celiac disease has been studied for more than thirty years. We review different etiologies of liver diseases and their possible association with celiac disease and seek to define in which situations serological screening should be performed.
\end{abstract}

Keywords: celiac disease, liver diseases, liver cirrhosis, alanine transaminase, autoimmune hepatitis

Cite This Article: Janaína Luz Narciso-Schiavon, and Leonardo L. Schiavon, "Is screening for Celiac Disease Needed in Patients with Liver Disease?.” International Journal of Celiac Disease, vol. 3, no. 3 (2015): 91-94. doi: 10.12691/ijcd-3-3-2.

\section{Introduction}

Celiac disease is a chronic immune-mediated inflammatory intestinal disorder induced by gluten ingestion in genetically susceptible individuals [1]. It differs substantially from other autoimmune diseases as immunosupressants are not part of the treatment. The diagnosis requires a joint clinicopathological approach; the recommended first-line test is serology with immunoglobulin A (IgA) tissue transglutaminase (tTG) and IgA endomysial (EmA) antibodies. These serological tests have high levels of sensitivity and specificity, but the presence of lymphocyte infiltrate and villous atrophy in small bowel biopsy is still the gold standard for confirming diagnosis [2]. As in many developing countries the tests for celiac disease are not available, clinicians and institutions should find ways to make confirmatory tests for celiac disease available. WakimFleming et al recently demonstrated that in cirrhotic patients, high titers for human tTG and EmA can diagnose celiac disease in the absence of a small bowel biopsy [3]. However, Carrocio et al pointed out that false positive human tTG can be observed in patients with chronic liver diseases [4]. These facts must be taken into account when facing suspected celiac disease.

Patients may present classical clinical manifestations (weight loss, anemia, diarrhea or general weakness), metabolic bone disease, iron, or folate deficiencies (osteoporosis, fractures, or anemia), or neurologic symptoms (ataxia, encephalopathy, or myelopathy) and associated autoimmune diseases that are often of greater clinical significance than celiac disease [5,6]. When gluten is removed from the diet, most patients present clinical remission and test negative for autoantibodies [7]. High aminotransferase levels of unknown etiology may also normalize with a gluten-free diet [8].

We aimed to perform a theoretical study of literature on screening of celiac disease in patients with liver disease.

\section{Material and Methods}

A review for liver involvement in celiac disease was performed by conducting a broad search for "celiac disease" AND "alanine transaminase" "liver cirrhosis" "portal hypertension" "autoimmune hepatitis" "primary biliary cirrhosis" "sclerosing cholangitis" "non-alcoholic fatty liver disease" in Pubmed. Additionally the references of the selected articles were also consulted for relevant articles on the subject. Only relevant full papers were included.

\section{Celiac Disease and the Liver}

Liver involvement in celiac disease has been studied for more than thirty years [9]. At present, celiac disease screening is recommended for all patients with abnormal liver blood tests, autoimmune liver diseases, prior interferon-based therapy for viral hepatitis, and cirrhosis of various etiologies [10,11]. A Czech study observed that $3 \%(29 / 962)$ of the individuals with liver diseases and $0.8 \%(5 / 523)$ who underwent liver transplant were seropositive for anti-tTG antibodies. However, celiac disease was biopsy-diagnosed in 16 patients: 4 with autoimmune hepatitis type I, 3 with Wilson's disease, 3 with "celiac hepatitis", 2 with primary sclerosing cholangitis, 1 with primary biliary cirrhosis, 1 with BuddChiari syndrome, 1 with toxic hepatitis, and 1 with nonalcoholic steatohepatitis. This study demonstrated that celiac disease may be present with any etiology of liver 
disease [11]. The fact that two diseases coexist does not mean that there is an association, and the most important questions here are whether there is evidence to recommend celiac disease screening in all patients with liver disease and whether there are possible benefits.

Among patients with cryptogenic hypertransaminasemia, about $3.6 \%$ to $4.1 \%$ present biopsy-proven celiac disease [12], and in most cases abnormal liver tests normalize with a gluten-free diet $[8,12]$. When they do not, liver biopsies are mandatory for further investigation of hepatic involvement, which has previously been related to chronic active hepatitis [8]. Nonetheless, when aminotransferase levels remain elevated, screening for autoimmune liver diseases such as autoimmune hepatitis (AIH), primary biliary cirrhosis (PBC), and primary sclerosing cholangitis (PSC) must be performed [13,14,15].

Celiac disease is ten times more prevalent among patients with AIH than in the general population [16]. When both diseases are present, the introduction of a gluten-free diet in immunosuppressed patients can cause a high AIH remission rate. When clinical remission is reached, a prolonged immunosuppressive regimen induces a high sustained remission rate after treatment withdrawal [17].

The association between PBC and celiac disease has long been suspected since Logan et al first reported both conditions diagnosed simultaneously in 4 patients [18]. The association remains controversial [19,20,21]. Nevertheless, a gluten-free diet may be helpful in restoration of liver function in patients with PBC and celiac disease [19].

Associations between PSC and celiac disease have been described by many authors [22,23]. One case series showed that anti-smooth muscle antibody (ASMA) was present in 3 patients with PSC, indicating that screening for celiac disease may be of value in patients with PSC specially in the presence of ASMA [22]. More studies including a large number of patients are necessary to define the association between autoimmune liver diseases and celiac disease. This question has not been answered because eating habits and celiac disease prevalence vary around the world. The primary concern at this point is whether patients with autoimmune liver disease should be actively screened for EmA and tTG antibodies, especially those with persistent altered liver tests, in regions where the prevalence of celiac disease is significant. In this context, a gluten-free diet may contribute to normalization of liver biochemistry, may halt progression of the liver disease, and may even prevent complications such as the onset of other autoimmune diseases or lymphoma.

It has been reported that nonalcoholic fatty liver disease (NAFLD) without metabolic syndrome could be related to the concomitant presence of celiac disease. Bardella et al evaluated 59 patients with hypertransaminasemia and biopsy-proven NAFLD, and 3.4\% were found to have celiac disease [24]. After 6 months of a gluten-free diet, liver enzymes normalized. It was later observed that a significant proportion of NAFLD patients, including obese individuals or those with metabolic syndrome, were seropositive for celiac disease, but EmA and tTG were more commonly found in those with body mass indices less than $27 \mathrm{~kg} / \mathrm{m}^{2}$. Additionally, their aminotransferase levels and ultrasound steatosis regressed with gluten-free diet $[25,26]$. A pathogenetic link between NAFLD and celiac disease involving gut permeability, microbiota, and diet has been proposed, but the pathogenesis of liver steatosis in celiac disease remains uncertain $[27,28]$. Patients with NAFLD should be screened for celiac disease when steatohepatitis is present in the absence of metabolic risk factors and once other causes of the liver disease are excluded [27].

Few studies have addressed the relationship between celiac disease and chronic hepatitis B [29,30], and the results are controversial. It has been demonstrated that vaccines against the hepatitis $B$ virus are less efficacious in patients with celiac disease [31,32]. While celiac disease is considered an autoimmune disorder, this reduced efficacy may reflect defective mechanisms in antibody production and viral clearance. A higher prevalence of celiac disease has been observed in those infected with hepatitis $\mathrm{C}$ virus (HCV) than those without it $[33,34]$. However, a French multi-center study failed to demonstrate such association, probably because of the low prevalence of celiac disease in France [35]. Despite the controversy over the link between these two diseases, the primary concern is that patients may present severe cases of overt celiac disease during HCV treatment, leading to discontinuation of interferon-alfa (IFN) [36]. Patients with both diseases may experience severe diarrhea with weight loss during IFN treatment as well as dermatitis herpetiformis, hypoferritinemia, and refractory anemia that persist after treatment has stopped. Until recently, the association of pegylated interferon-alfa (PEG) with ribavirin was the gold standard treatment for hepatitis $\mathrm{C}$ [37]. All HCV patients should be screened for celiac disease prior to anti-viral treatment. For those with positive antibodies, IFN-free regimens are the logical choice. If the new drugs (protease inhibitors of $2^{\text {nd }}$ and $3^{\text {rd }}$ generation) are not available, a gluten-free diet must be started preemptively, and patients should be carefully monitored during IFN treatment [34,36,38].

Some case reports have suggested that celiac disease may be a trigger for the development of idiopathic noncirrhotic intrahepatic portal hypertension (NCIHPH) $[39,40]$. In India, $10 \%$ of NCIHPH patients had biopsyproven celiac disease[41]. Furthermore, the presence of celiac disease predicts reduced transplant-free survival [42]. Current data suggests the need to search for celiac disease in all patients with unexplained portal hypertension [41], although we do not know if a gluten-free diet can change the evolution of the disease or improve survival.

Celiac disease is at least twice more common in cirrhotic patients than in the general population [3]. The absence of a common histological pattern of liver injury in patients with celiac disease does not favor the assumption that this disease directly damages the liver [43]. Kaukinen et al described patients with chronic liver disease before or after liver transplant in which detection and treatment of celiac disease prevented progression to end-stage liver failure. Three were in consideration for liver transplant. Hepatic dysfunction reversed in all patients when a glutenfree diet was adopted [44]. Besides these, other cases were reported where decompensated cirrhosis reversed after the introduction of a gluten-free diet $[43,45,46]$. These data indicate that celiac disease should be screened in cirrhotic patients, especially in those with hypoalbuminemia and ascites [3,43]. Independent of the etiology of liver cirrhosis, patients with advanced liver disease and celiac disease may benefit from a gluten-free diet. 


\section{Conclusion}

Although major advances were made over the last decades, future studies are still needed to define the prevalence of celiac disease in various etiologies of liver diseases and to prove any alleged association. Also, the impact of celiac disease in several etiologies of liver disease is yet to be determined. Based on the current knowledge, serologic screening for celiac disease should be done in the setting of cryptogenic hypertransaminasemia, autoimmune liver diseases, NAFLD in the absence of classical risk factors, idiopathic noncirrhotic portal hypertension, and advanced cirrhosis of any etiology.

\section{References}

[1] Freeman HJ. Celiac disease: a disorder emerging from antiquity, its evolving classification and risk, and potential new treatment paradigms. Gut and liver 2015; 9(1): 28-37.

[2] Walker MM, Murray JA. An update in the diagnosis of coeliac disease. Histopathology 2011; 59(2): 166-179.

[3] Wakim-Fleming J, Pagadala MR, McCullough AJ, Lopez R, Bennett AE, Barnes DS, Carey WD. Prevalence of celiac disease in cirrhosis and outcome of cirrhosis on a gluten free diet: a prospective study. Journal of hepatology 2014; 61(3): 558-563.

[4] Carroccio A, Soresi M, Di Prima L, Montalto G. Screening for celiac disease in patients with chronic liver disease. Gastroenterology 2003; 125(4): 1289; author reply 1289-1290.

[5] Green PH, Jabri B. Coeliac disease. Lancet 2003; 362(9381): 383391.

[6] Hadjivassiliou M, Sanders DS, Grunewald RA, Woodroofe N, Boscolo S, Aeschlimann D. Gluten sensitivity: from gut to brain. The Lancet Neurology 2010; 9(3): 318-330.

[7] Hall NJ, Rubin G, Charnock A. Systematic review: adherence to a gluten-free diet in adult patients with coeliac disease. Alimentary pharmacology \& therapeutics 2009; 30(4): 315-330.

[8] Bardella MT, Fraquelli M, Quatrini M, Molteni N, Bianchi P, Conte D. Prevalence of hypertransaminasemia in adult celiac patients and effect of gluten-free diet. Hepatology (Baltimore, $M d$ ) 1995; 22(3): 833-836.

[9] Lindberg J, Ahren C, Jonsson J. Gluten-free diet in chronic active hepatitis associated with intestinal villous atrophy. Hepatogastroenterology 1982; 29(2): 52-54.

[10] J.L. N-S, L.L. S. Should Patients with Liver Disease be Screened for Celiac Disease? J Res Development 2014; 116(2).

[11] Drastich P, Honsova E, Lodererova A, Jaresova M, Pekarikova A, Hoffmanova I, Tuckova L, Tlaskalova-Hogenova H, Spicak J, Sanchez D. Celiac disease markers in patients with liver diseases: a single center large scale screening study. World journal of gastroenterology: WJG 2012; 18(43): 6255-6262.

[12] Sainsbury A, Sanders DS, Ford AC. Meta-analysis: Coeliac disease and hypertransaminasaemia. Alimentary pharmacology \& therapeutics 2011; 34(1): 33-40.

[13] Vajro P, Paolella G, Pisano P, Maggiore G. Hypertransaminasemia and coeliac disease. Alimentary pharmacology \& therapeutics 2012; 35(1): 202-203; author reply 203-204.

[14] Duggan JM, Duggan AE. Systematic review: the liver in coeliac disease. Alimentary pharmacology \& therapeutics 2005; 21(5): 515-518.

[15] Rodrigo L. Celiac disease. World journal of gastroenterology : WJG 2006; 12(41): 6585-6593.

[16] van Gerven NM, Bakker SF, de Boer YS, Witte BI, Bontkes H, van Nieuwkerk CM, Mulder CJ, Bouma G. Seroprevalence of celiac disease in patients with autoimmune hepatitis. European journal of gastroenterology \& hepatology 2014; 26(10): 11041107.

[17] Di Biase AR, Colecchia A, Scaioli E, Berri R, Viola L, Vestito A, Balli F, Festi D. Autoimmune liver diseases in a paediatric population with coeliac disease - a 10-year single-centre experience. Alimentary pharmacology \& therapeutics 2010; 31(2): 253-260.
[18] Logan RF, Ferguson A, Finlayson ND, Weir DG. Primary biliary cirrhosis and coeliac disease: an association? Lancet 1978; 1(8058): 230-233.

[19] Habior A, Lewartowska A, Orlowska J, Zych W, Sankowska M, Bauer A, Butruk E. Association of coeliac disease with primary biliary cirrhosis in Poland. European journal of gastroenterology \& hepatology 2003; 15(2): 159-164.

[20] Gillett HR, Cauch-Dudek K, Jenny E, Heathcote EJ, Freeman HJ. Prevalence of IgA antibodies to endomysium and tissue transglutaminase in primary biliary cirrhosis. Canadian journal of gastroenterology = Journal canadien de gastroenterologie 2000; 14(8): 672-675.

[21] Chatzicostas C, Roussomoustakaki M, Drygiannakis D, Niniraki M, Tzardi M, Koulentaki M, Dimoulios P, Mouzas I, Kouroumalis E. Primary biliary cirrhosis and autoimmune cholangitis are not associated with coeliac disease in Crete. BMC gastroenterology 2002; 2: 5.

[22] Al-Osaimi AM, Berg CL. Association of primary sclerosing cholangitis and celiac disease: a case report and review of the literature. Digestive diseases and sciences 2004; 49(3): 438-443.

[23] Gillberg R, Dotevall G, Ahren C. Chronic inflammatory bowel disease in patients with coeliac disease. Scandinavian journal of gastroenterology 1982; 17(4): 491-496.

[24] Bardella MT, Valenti L, Pagliari C, Peracchi M, Fare M, Fracanzani AL, Fargion S. Searching for coeliac disease in patients with non-alcoholic fatty liver disease. Digestive and liver disease : official journal of the Italian Society of Gastroenterology and the Italian Association for the Study of the Liver 2004; 36(5): 333-336.

[25] Grieco A, Miele L, Pignatoro G, Pompili M, Rapaccini GL, Gasbarrini G. Is coeliac disease a confounding factor in the diagnosis of NASH? Gut 2001; 49(4): 596.

[26] Rahimi AR, Daryani NE, Ghofrani H, Taher M, Pashaei MR, Abdollahzade S, Kalani M, Ajdarkosh H. The prevalence of celiac disease among patients with non-alcoholic fatty liver disease in Iran. The Turkish journal of gastroenterology : the official journal of Turkish Society of Gastroenterology 2011; 22(3): 300-304.

[27] Abenavoli L, Luigiano C, Larussa T, Milic N, De Lorenzo A, Stelitano L, Morace C, Consolo P, Miraglia S, Fagoonee S, Virgilio C, Luzza F, Pellicano R. Liver steatosis in celiac disease: the open door. Minerva gastroenterologica e dietologica 2013; 59(1): 89-95.

[28] Abenavoli L, Milic N, De Lorenzo A, Luzza F. A pathogenetic link between non-alcoholic fatty liver disease and celiac disease. Endocrine 2013; 43(1): 65-67.

[29] Nau AL, Fayad L, Lazzarotto C, Shiozawa MB, Dantas-Correa EB Schiavon Lde L, Narciso-Schiavon JL. Prevalence and clinical features of celiac disease in patients with hepatitis B virus infection in Southern Brazil. Revista da Sociedade Brasileira de Medicina Tropical 2013; 46(4): 397-402.

[30] Leonardi S, La Rosa M. Are hepatitis B virus and celiac disease linked? Hepatitis monthly 2010; 10(3): 173-175.

[31] Ertekin V, Tosun MS, Selimoglu MA. Is there need for a new hepatitis B vaccine schedule for children with celiac disease? Hepatitis monthly 2011; 11(8): 634-637.

[32] Rostami Nejad M, Rostami K, Zali MR. Hepatitis B vaccination reliability in celiac disease. Hepatitis monthly 2011; 11(8): 597598.

[33] Fine KD, Ogunji F, Saloum Y, Beharry S, Crippin J, Weinstein J. Celiac sprue: another autoimmune syndrome associated with hepatitis C. The American journal of gastroenterology 2001; 96(1): 138-145.

[34] Durante-Mangoni E, Iardino P, Resse M, Cesaro G, Sica A, Farzati B, Ruggiero G, Adinolfi LE. Silent celiac disease in chronic hepatitis C: impact of interferon treatment on the disease onset and clinical outcome. Journal of clinical gastroenterology 2004; 38(10): 901-905.

[35] Thevenot T, Denis J, Jouannaud V, Monnet E, Renou C, Labadie $\mathrm{H}$, Abdelli N, Nguyen-Khac E, Dumouchel P, Bresson-Hadni S, Chousterman M, V DIM, Cadranel JF. Coeliac disease in chronic hepatitis C: a French multicentre prospective study. Alimentary pharmacology \& therapeutics 2007; 26(9): 1209-1216.

[36] Narciso-Schiavon JL, L. SL. Autoantibodies in Chronic Hepatitis C: a Clinical Perspective. World Journal of Hepatology 2015; 7(5): 1074-1085.

[37] Ghany MG, Nelson DR, Strader DB, Thomas DL, Seeff LB. An update on treatment of genotype 1 chronic hepatitis $C$ virus infection: 2011 practice guideline by the American Association for 
the Study of Liver Diseases. Hepatology (Baltimore, Md) 2011; 54(4): 1433-1444.

[38] Adinolfi LE, Durante Mangoni E, Andreana A. Interferon and ribavirin treatment for chronic hepatitis C may activate celiac disease. The American journal of gastroenterology 2001; 96(2): 607-608.

[39] Zamani F, Amiri A, Shakeri R, Zare A, Mohamadnejad M. Celiac disease as a potential cause of idiopathic portal hypertension: a case report. Journal of medical case reports 2009; 3: 68.

[40] Sharma BC, Bhasin DK, Nada R. Association of celiac disease with non-cirrhotic portal fibrosis. Journal of gastroenterology and hepatology 2006; 21(1 Pt 2): 332-334.

[41] Maiwall R, Goel A, Pulimood AB, Babji S, Sophia J, Prasad C, Balasubramanian KA, Ramakrishna B, Kurian S, Fletcher GJ, Abraham P, Kang G, Ramakrishna BS, Elias E, Eapen CE. Investigation into celiac disease in Indian patients with portal hypertension. Indian journal of gastroenterology : official journal of the Indian Society of Gastroenterology 2014; 33(6): 517-523.
[42] Eapen CE, Nightingale P, Hubscher SG, Lane PJ, Plant T, Velissaris D, Elias E. Non-cirrhotic intrahepatic portal hypertension: associated gut diseases and prognostic factors. Digestive diseases and sciences 2011; 56(1): 227-235.

[43] Ratziu V, Nourani M, Poynard T. Discussion on celiac disease in patients with severe liver disease: gluten-free diet may reverse hepatic failure. Gastroenterology 2002; 123(6): 2158-2159; author reply 2159-2160.

[44] Kaukinen K, Halme L, Collin P, Farkkila M, Maki M, Vehmanen P, Partanen J, Hockerstedt K. Celiac disease in patients with severe liver disease: gluten-free diet may reverse hepatic failure. Gastroenterology 2002; 122(4): 881-888.

[45] Al-Hussaini A, Basheer A, Czaja AJ. Liver failure unmasks celiac disease in a child. Annals of hepatology 2013; 12(3): 501-505.

[46] Roumeliotis N, Hosking M, Guttman O. Celiac disease and cardiomyopathy in an adolescent with occult cirrhosis. Paediatrics \& child health 2012; 17(8): 437-439. 